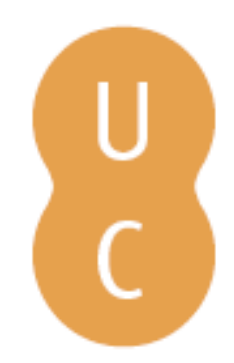

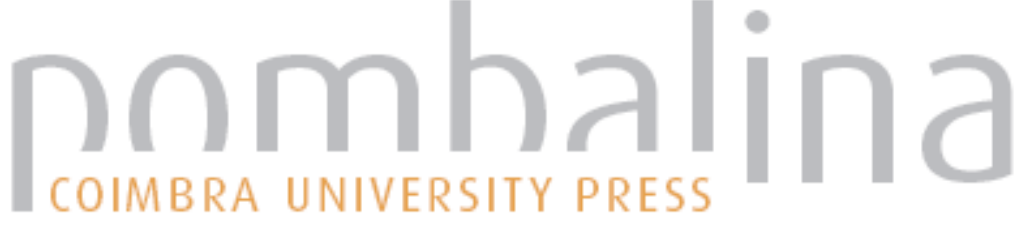

\section{Paisagens marinhas no Hipólito de Eurípides}

Autor(es): $\quad$ Fialho, Maria do Céu

Publicado por: Associação Portuguesa de Estudos Clássicos; Imprensa da

Universidade de Coimbra

URL

persistente: URI:http://hdl.handle.net/10316.2/31742

DOI: $\quad$ DOI:http://dx.doi.org/10.14195/978-989-721-069-3_2

Accessed : $\quad$ 26-Apr-2023 08:52:44

A navegação consulta e descarregamento dos títulos inseridos nas Bibliotecas Digitais UC Digitalis, UC Pombalina e UC Impactum, pressupõem a aceitação plena e sem reservas dos Termos e Condições de Uso destas Bibliotecas Digitais, disponíveis em https://digitalis.uc.pt/pt-pt/termos.

Conforme exposto nos referidos Termos e Condições de Uso, o descarregamento de títulos de acesso restrito requer uma licença válida de autorização devendo o utilizador aceder ao(s) documento(s) a partir de um endereço de IP da instituição detentora da supramencionada licença.

Ao utilizador é apenas permitido o descarregamento para uso pessoal, pelo que o emprego do(s) título(s) descarregado(s) para outro fim, designadamente comercial, carece de autorização do respetivo autor ou editor da obra.

Na medida em que todas as obras da UC Digitalis se encontram protegidas pelo Código do Direito de Autor e Direitos Conexos e demais legislação aplicável, toda a cópia, parcial ou total, deste documento, nos casos em que é legalmente admitida, deverá conter ou fazer-se acompanhar por este aviso.

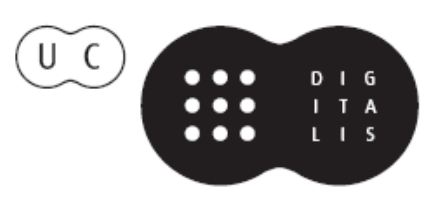




\section{Espaços e Paisagens}

\section{Antiguidade Clássica e Heranças Contemporâneas}

Vol. I Línguas e Literaturas. Grécia e Roma

Francisco de Oliveira, Cláudia Teixeira, Paula Barata Dias (coords.)

IMPRENSA DA UNIVERSIDADE DE COIMBRA 


\title{
PAISAGENS MARINHAS NO HIPÓLITO DE EURÍPIDES
}

\author{
Maria do Céu Fialho \\ Universidade de Coimbra
}

\begin{abstract}
The main sites in the play are essentially three: the city, the countryside visited by Hippolytus and his companions, and the sea. Divine action and its meaning intertwines with these three spaces of action. At first sight it appears as a domain of oppositions, but in fact it is a domain of complementarity. The aim of this paper is to understand this intertwining process and its importance to the reading of this tragedy.
\end{abstract}

Keywords: Aphrodite, Artemis, Hippolytus, Poseidon, sea, wild nature.

Palavras-chave: Afrodite, Ártemis, Eurípides, Hipólito, mar, natureza selvagem, Poséidon.

A cisão cartesiana entre sujeito, como entidade que pensa, e objecto, como uma alteridade susceptível de ser pensada, observada e dominada por esse mesmo pensamento abriu um caminho que, como é sabido, nos conduziu até à perspectiva tecnológica e tecnocrática que veio crescendo até à contemporaneidade. $\mathrm{O}$ homem de hoje apercebe-se, finalmente, dos limites e dos perigos desta dinâmica levada às últimas consequências. $\mathrm{O}$ pretenso "domínio" da Natureza despoletou consequências catastróficas que atestam a sua dimensão indominável.

Tal cisão afecta o modo como o homem se vê no mundo e como vê o mundo. Assim, o termo 'paisagem', que nos chegou do francês e que tem uma composição análoga ao do inglês 'landscape' ou do alemão 'Landschaft', ainda que assente na noção de 'terra' a que o homem está iniludivelmente ligado, tomou, cada vez mais, a carga de uma alteridade que os olhos humanos apreciam, e em que repousam, que os artistas observam para recriar, que a mão humana altera. 'Paisagem' como 'quadro da natureza', onde o homem pode, também, entrar para seu repouso e fruição, opunha-se, implicitamente, a espaço urbano. É relativamente recente a noção de 'paisagem urbana', ainda assim com a carga mista de valorização ou desvalorização do espectáculo do espaço construído pelo homem e de espaço de intervenção do homem, em função de uma melhor habitabilidade.

Este último cambiante revela já a abertura da contemporaneidade para uma simbiose necessária, em nome do equilíbrio ecológico, entre espaço de habitação humano e natureza como mundo habitável a que o homem pertence como parte integrante a que tem de respeitar. Esta nova perspectiva nasceu da consciência de ameaça e conduz, curiosamente, sem que muitos disso se 
apercebam, à noção implícita do mundo como oikos conjunto, de que o homem também faz parte - uma vivência determinante nas matrizes gregas da nossa civilização.

Assim, aquilo que, ao homem moderno, pode soar como "descrição de paisagem" na poesia grega, como "escapismo", na tragédia grega, documentado na descrição de "paisagens ideais", harmónicas e longínquas, não o é, na realidade. Chora é a terra a que o homem pertence, com o seu espaço urbano, a natureza, stricto sensu, trabalhada ou não, é, enfim, extensão de pertença mútua passível de coincidir com a pátria-pólis. É sagrada, a partir de núcleos determinados, temenoi, altares ou templos que condensam e assinalam materialmente a presença divina e assumem a força energética de a difundir. Deuses, homens, animais, vegetação coexistem num ritmo harmónico, de acordo com a natureza específica e o âmbito de poder e acção da cada um.

As descrições poéticas trazem, pois, uma fortíssima carga semântica, um sentido profundo que serve de horizonte ao sentido da acção humana enquanto sintónica ou distónica com a natureza - que é a sua própria natureza. Há que entender assim, por exemplo, os dois mais famosos elogios poéticos a Atenas, o estásimo III de Medeia e o estásimo I de Édipo em Colono, entoados como voz da harmonia de uma terra que acolhe quem nela procura refúgio, selado o pacto de acolhimento entre o representante de Atenas - Egeu, na primeira das peças, Teseu na segunda - e Medeia, na peça homónima, ou o velho Édipo, na última tragédia de Sófocles.

Em Hipólito as alusões ou descrições da natureza primam pela ambiguidade. E essa ambiguidade levaria, certamente, o espectador do tempo ao cerne do sentido do mythos, proposto na dramatização euripidiana. É já Afrodite, no prólogo, quem dá o tom (29-33): Antes de volver a Trezena [Fedra], tomada de amores por um amor ausente, mandou erguer, junto à rocha de Palas, um templo a Cípris, visível desta terra. Doravante se dirá que a deusa tem ai o seu assento por causa de Hipólito.

O texto é ambíguo, já que o grego Hippolythoi ...epi (v. 32) ${ }^{1}$ pode ser indicativo de proximidade 'próximo de Hipólito' ou de causalidade 'por causa de Hipólito'. De facto, perto do temenos de Afrodite existia no séc. V, consoante testemunhos antigos, um monumento funerário em honra do filho da Amazona. Virado a sul, o templo seria potencialmente visto em Trezena, para além das águas do Golfo Sarónico ${ }^{2}$.

${ }^{1}$ A preposição epi, com regência de dativo, dá com maior frequência o sentido de proximidade, no mesmo plano ou em plano superior. De facto, W. S. Barrett (paperback 1992), Euripides. Hippolytos. Ed.w. introd. and comm. Oxford, 5, [Barrett] faz referência a dois espaços de culto a Hipólito, em que Afrodite tinha também lugar de veneração: um em Trezena, onde a deusa recebia culto como Aphrodite Kataskopia, segundo o testemunho de Pausânias, 2.32.3, outro em Atenas, com a presença de Aphrodite en Hippolytheioi ou epi Hippolytoi, testemunhado por uma inscrição de 423/422. Ainda assim, o eminente helenista defende, neste passo, o sentido causal (comm. ad 32-33). F. Lourenço, na sua tradução, mantém o efeito da ambiguidade: por intermédio de Hipólito.

${ }^{2}$ Digo 'potencialmente' dada a vasta extensão de águas que medeia entre a Ática e a costa junto à qual fica Trezena. 
As águas marinhas são elemento de Afrodite, berço de onde nasceu. A própria Ama, no seu discurso sofístico a Fedra, sobre essa espécie de cosmogonia cípria, sublinha a presença de Afrodite nas ondas do mar (447-448). E a própria Fedra, no seu famoso monólogo, invoca a "soberana Cípris, marinha" (415). Aparentemente, ao espaço marinho, conotado com Afrodite, se oporia o espaço da terra, para além dos limites da urbe, intransposto pelo comum dos mortais que a terra trabalham ou que guiam os rebanhos: os prados virgens de onde Hipólito chega, no início da peça, que ele frequenta, no que pensa ser um ostensivo e exclusivo convívio com a presença de Ártemis, a deusa caçadora (73 sqq.). Do seu espaço existencial pensa ter arredado Afrodite, cultivando, assim, uma eterna e intemporal virgindade.

O final da sua súplica, no prólogo (possa eu chegar ao termo da corrida da vida do mesmo modo que a comecei, v. 87), indicia a sua firme vontade de se manter alheio ao curso normal da vida humana, da historicidade do cidadão que cumpre o ritmo da existência, funda ou continua casa, tem filhos. Hipólito pressupõe que nada tem de aprender (hosois didakton meden, v. 79), numa pureza intacta e superior da sua sophrosyne onde só Ártemis cabe: ou melhor, a sua concepção de Ártemis ${ }^{3}$.

Assim entende Hipólito o próprio âmbito de exclusividade da deusa que venera. E, todavia, Fedra, no seu devaneio amoroso, anseia por se juntar a Hipólito nesse mesmo espaço, qual caçadora, depreende-se, unida à presa (vv. 215-222). Nos prados de Ártemis volitam as abelhas (v. 77), na sua incessante tarefa de fecundação. Como o volitar da abelha canta o Coro, no estásimo I (563-564), o envolvimento de Cípris em relação àqueles que atinge ${ }^{4}$. E atingeos também, ainda que a peça o não refira, como o caçador em perseguição da caça, actividade tão querida a Hipólito, por o aproximar de Ârtemis. Os animais selvagens são pertença do espaço de Ártemis, todavia, ainda a poldra indomada é susceptível da submissão ao jugo, como a donzela da Ecália, Íole, o é ao poder de Afrodite (estásimo I).

Esta ambiguidade, já notada por Segal ${ }^{5}$ e Zeitlin ${ }^{6}$, estende-se ao espaço marinho e à sua proximidade, a praia. Da costa norte do Golfo Sarónico, junto a Trezena, se avista o templo ateniense de Afrodite, no sopé da Acrópole, não longe do monumento funerário a Hipólito. Nessa mesma costa, a norte de

\footnotetext{
${ }^{3}$ Sobre esta dimensão da figura de Hipólito, a sua persistência em se manter à margem do curso da historicidade humana, num mundo idealizado, sem evolução nem aprendizagem, vejase F. Zeitlin: 1985: 66-67.

${ }^{4}$ Nota Barrett, comm. ad 563-564, que a imagem de Eurípides sublinha, essencialmente, a imprevisibilidade, no voo da abelha, do sítio onde vai pousar: assim se reforça a ideia de que Afrodite e Eros são imprevisíveis na sua acção sobre os mortais.

${ }^{5}$ C. Segal (1965: 117-169) dedica todo o seu trabalho a esta rede de ambiguidades. Vejase M. C. Fialho, (1996: 47) onde cito, além do mais, a pertinente observação de Burkert: há, em Ártemis e no seu cortejo, um erotismo latente. Por outro lado, sabemos que, do cortejo de Afrodite pelos bosques, fazem parte os grandes felinos selvagens. Ora, como nota M. P. Nilsson (1967: 488) há notícia da oferenda, por ocasião das festividades em honra de Ártemis Ortia, de um grande queijo feito de leite de leoa à deusa.

${ }^{6}$ Op. cit. 52-111.
} 
Trezena, tem Ártemis um espaço sagrado, nas águas salgadas da Lagoa, cantada pelo Coro no párodo (148-150), a "senhora da Lagoa", conforme Fedra invoca Ártemis Sarónica $(228)^{7}$. Ou seja, a costa de que se avista o espaço sagrado de Afrodite, associada a Hipólito, está sob o signo da proximidade do espaço sagrado de Ártemis, fundido com o das águas marinhas.

Dictina, a deusa cretense, da terra natal de Fedra, portanto, invocada no párodo por um Coro que se interroga sobre a origem dos males de Fedra, é, na religião grega, assimilada a Ártemis. Também aquela é protectora dos animais selvagens. Mas é, todavia, em Creta, para além disso, patrona dos pescadores - daqueles que entram, assim, no elemento salgado de onde Afrodite nasceu. Nilsson aponta a derivação do nome da deusa cretense a partir de diktyon, 'rede': comum à caça e à pesca ${ }^{8}$.

De Creta, espaço de Dictina, trouxe o "navio de velas brancas", "através da onda ...do mar salgado" a noiva para as núpcias fatais, consoante o Coro o recorda no estásimo II, até ao porto de Muníquia, sob a égide de Ártemis - o que evoca uma outra proximidade: a de um outro espaço sagrado, também sob a égide de Ártemis, de ritual de passagem da jovenzinha da infância à idade núbil: Bráuron. Conclui Burkert: "There is no wedding without Artemis: hers is the power to send and ward off dangers before and after this decisive turning-point in a girl's life" 9 . Ela é a senhora dos partos, assimilada a Ilitia. Não há Ártemis sem Afrodite e da acção de Afrodite-Eros se gera mundo e novos seres, para a tutela de Ártemis.

Hipólito projecta, nos espaços que frequenta, a unilateralidade da sua visão de mundo. Mas os espaços falam de uma outra realidade mais rica e mais profunda, que é a do universo humano e divino pautado pelo ritmo de uma lei universal da Natureza. Os espaços marinhos ilustram-no, com particular eloquência, ainda que Hipólito frequente a sua proximidade, sem de tal se aperceber. Na praia treina os cavalos - à beira de Ártemis, mas também de Afrodite - na praia chora o seu exílio. A sua queda, fruto da vingança de Afrodite ou do que a deusa representa, dar-se-á, metafórica e literalmente, na sequência dos votos de Teseu, à beira de ambas as deusas, no promontório selvagem, sobranceiro ao mar. É Poséidon, deus do mar e deus do solo, 'o que abala a terra', o agente invocado para a sua destruição.

Nas suas competências, o deus alia a sua presença, quase como entidade unificadora, aos espaços terrestres mais marcados pela égide de Ártemis aqueles em que Hipólito exercita os seus cavalos - e aos espaços marinhos,

\footnotetext{
${ }^{7}$ Nilsson, op.cit. 492-493, nota que, no Peloponeso, Ártemis e o seu culto andam também associados a fontes, pântanos e depressões de terreno ricos em água. Quanto ao culto de Ártemis Sarónia, com um bosque sagrado que lhe era dedicado, à beira da lagoa salgada, na costa, junto a Trezena, refere o autor o testemunho de Pausânias 2.30.7. Cf. Barrett comm. ad 148-150. O mesmo Nilsson lembra a profusão de espaços sagrados dedicados a Ártemis, Afrodite e às Ninfas na foz do rio Alfeu (rio que o Coro canta no estásimo I).

${ }^{8}$ Op. cit. 311. Sobre as equivalências teológicas de Dictina, Ilitia, Hécate, Cíbele e Ártemis, efectivas na religião grega e evocadas pelo Coro de Hipólito no párodo, veja-se M. C. Fialho 4344 e a bibliografia aí indicada.

${ }^{9}$ W. Burkert 1985: 151.
} 
onde Ártemis está presente, na Lagoa do Golfo Sarónico, mas onde Afrodite tem o seu âmbito de proveniência. $O$ deus que abala a terra faz tremer os fundamentos desta e a carreira certa de Hipólito, para se elevar, como gigantesca onda marinha de maremoto, e se abater, sob a forma de um touro gigantesco, sobre o destino de Hipólito.

O touro é, em todas as iconografias e no imaginário grego também, símbolo material de potência viril, de força natural de uma sexualidade violenta e incontrolável. Nem Hipólito, na sua mestria de auriga virginal, que pretende concluir a sua corrida consoante a começou, o pode evitar e fazer-lhe frente, a ele, Poséidon, o deus que ensinou a domar os cavalos e a pôr-lhes o freio, como canta o Coro do estásimo I de Édipo em Colono. Nesse aspecto, o deus actua, efectivamente, como mestre da domesticação, num âmbito que serve de fonte à linguagem figurada da passagem da virgindade à submissão amorosa: a donzela admetos, olhada na lírica erótica como objecto do desejo, tenderá a conhecer o jugo imposto pela força de eros. Assim o refere o Coro em relação a Íole, a poldra da Ecália, azyga lektron, , anandron, anymphon (545-547) logo «subjugada» por Héracles.

Hipólito despenhar-se-á do promontório, para aquele espaço sobre o mar, sobranceiro às águas de Afrodite e não desvinculado de Ártemis. A sua corrida não pode, pois, terminar como começou - homem algum pode fazer coincidir princípio e termo. Lembrando Alcméon de Crotona (frg. 2B, DK), dizem que é por este motivo que os homens morrem: por não poderem ligar o princípio com of fim. É esse o preço da historicidade humana.

No seu fim, Ártemis o compensará de um modo que ao espectador pode parecer fraca recompensa concedida àquele que tão fielmente a venerou (ainda que da deusa tenha tido uma concepção empobrecida, fruto da projecção da sua própria mundividência e natureza): um culto será instituído, que perpetuará a memória do jovem. As donzelas, antes de casar, cortarão madeixas do seu cabelo em sua honra e chorarão a sua sorte. A grande compensação reside, afinal, na verdadeira integração de Hipólito, ainda que post mortem, no grande ciclo da vida: ele ficará associado ao limiar da passagem do âmbito de uma deusa para o de outra. E não há espaço sagrado, em Trezena ou Atenas, que, consagrado a Hipólito, não tenha Afrodite por perto. A tensão entre as deusas continua - mas essa tensão é a própria violência da natureza, nas fases do seu ciclo vital. E tensão significa coexistência de uma por dentro do reino da outra, no espaço natural em que o homem se enraiza e que representa o seu mundo. Uma e outra se encaram e completam, frente a frente, de costa para costa no Golfo Sarónico, entre Trezena e Atenas.

\section{Bibliografia}

W. S. Barrett (paperback 1992), Euripides. Hippolytos. Ed. w. introd. and comm. Oxford.

W. Burkert (trad. ingl.1985), Greek Religion Oxford. 
M. C. Fialho (1996), "Afrodite e Ártemis no Hipólito de Eurípides”, Máthesis 5 33-51.

F. Lourenço (21996), Eurípides. Hipólito, trad. introd. notas. Lisboa.

P. Nilsson (1967), Geschichte der griechischen Religion, Bd. I München.

C. Segal (1965), "The Tragedy of Hyppolytos: the Waters of the Ocean and the Untouched Meadow", HSCPh 70 117-169.

F. Zeitlin (1985), "The Power of Aphrodite: Eros and the Boundaries of the Self in the Hippolytus" in P. Burian (ed.), Directions in Euripidean Criticism. A Collection of Essays. Durham 52-111. 